\title{
Mini-review on Bubbfil spinning process for mass-production of nanofibers
}

\author{
${ }^{1}$ Nantong Textile Institute, Soochow University, Nantong, China \\ ${ }^{2}$ National Engineering Laboratory for Modern Silk, College of Textile and Clothing Engineering, Soochow University, 199 \\ Ren-Ai Road, Suzhou, China \\ e-mail: hejihuan@suda.edu.cn
}

\section{ABSTRACT}

Bubbfil spinning is to use polymers' or melts' bubbles or membranes for fabrication of nanomaterials including smooth nanofibers and discontinuous nanofibers by using electrostatic force, blowing air or mechanical force to overcome the surface tension, it mainly includes the bubble-electrospinning, blown bubble spinning and membrane spinning. The initial ejecting velocity of the Bubbfil spinning process is as high as 100 meters per second. A history of the development of Bubbfil spinning is briefly elucidated, its main properties are emphasized, some effective modifications are discussed for different applications including single bubble electrospinning, blown bubble spinning, air-jet assisted bubble electrospinning, electrostatic-field-assisted blown bubble spinning, and vibration bubble electrospinning which is suitable for melts or high-concentration solutions. Morphology properties are also discussed for different applications.

Keywords: Bubble electrospinning, modifications, development, properties.

\section{INTRODUCTION}

With nanometer era's advent, nanotechnology will deeply affect both human's life and modern science, and it is of indispensable importance for the scientific and economical revival. Generally, nanomaterials can remarkably enhance the mechanical properties, remarkably improve surface energy and surface reactivity, and have excellent thermal and electric conductivity, independent of their bulk materials. Because of ultra improvement of the high specific surface, nanoporous materials are potentially of great technological interest for the development of electronic, catalytic and hydrogen-storage systems, invisibility device (e.g. stealth plane), photonic structures, sensors, medicine, pharmacy and drug deliver, adsorption, separation, filtering, catalysis, fluid storage and transport, electrode materials or as reactors. Far-reaching implications are emerging for applications including radiation protection, medical implants, cell supports, materials that can be used as instructive three-dimensional environments for tissue regeneration and others [1]. But the nanoindustrialization is still under development, in this review article, we give a detailed introduction to a new technology for mass-production of nanofiber, which is termed as Bubbfil spinning process [2] where polymer/melts bubbles/membranes are used for fabrication of nanofibers using electrostatic force, flowing air or mechanical force (e.g. centrifugal force) to overcome the surface tension of bubbles, including the bubbleelectrospinning [ $\underline{3}-\underline{10}]$, blown bubble spinning [ $\underline{11}, \underline{12}]$, membrane spinning [13, $\underline{14]}$ and others. Before introduction to the new technology, we begin with electrospinning [15-19], which is the simplest way to producing ultrafine fibers with diameters ranging from $10^{\mu m}$ down to $10 \mathrm{~nm}$ by forcing a viscous polymer solution or melt through a spinnerette with an electric field. When the electric force overcomes its surface tension of the Taylor cone, a charged jet is formed.

The surface tension for the polymer solution can be expressed in the form [20] 


$$
\sigma=A e^{-B / \eta}
$$

where $\sigma$ is the surface tension, $\eta$ is the viscosity, $\mathrm{A}$ and $\mathrm{B}$ are constants. According to Mark-Houwink formulation $[\underline{21}, \underline{22}]$, a higher molecular weight of a solution yields a higher viscosity:

$$
\eta \propto M_{w}^{\alpha}
$$

Where $M_{w}$ is the molecular weight, $\alpha$ is the scaling exponent, the value of $\alpha$ lies between $1 / 3$ and 1 .

Eqs.(1) and (2) imply that higher viscosity or higher molecular weight results in higher surface tension of the Taylor cone, as a result, a higher electrostatic force is needed. When the molecular weight/viscosity increases to a threshold, the polymer solution becomes coagulated, and cannot be used for fabrication of ultrafine fibers by the classical electrospinning [23]. There are other disadvantages for the electrospinning, e.g., low production ratio, in controllability of the spinning process. To overcome these problems, few technologies were appeared [1] , among which the bubble-electrospinning [ $\underline{3}-\underline{9}$ ] has been caught much attention, and it has been developed into a matured technology termed as Bubbfil spinning process [2], which is a potential candidate for mass production of various nanomaterials, including smooth nanofibers, nanoparticles, thin films, nanoporous materials and crimped nanofibers [24].

\section{BUBBLE ELECTROSPINNING}

Bubble-electrospinning [ $\underline{3}-\underline{10}$ ], the initial stage of Bubbfil spinning process [2] , was first invented in 2007 by Ji-Huan He and his collogues (CHN Patent No. ZLGL2007030001), which has an intrinsic property that uses an electrostatic force to overcome the surface tension of a polymer bubble instead of that of a Taylor cone in classic electrospinning, however, it is very difficult to control the bubble number on the solution surface [25]. To overcome the shortcoming Ji-Huan He and his collogues patented a single bubble electrospinning system (CHN Patent No. 200710036447.4), where only one single bubble is produced [26], such experimental is suitable for scientific analysis but not for industrial applications. It is, therefore, very much urgent to design a suitable bubble electrospinning system that can be used for both scientific analysis and mass-production of micro/nano fibers.

\subsection{Young-Laplace Equation}

It is interesting to be noted that the surface tension of a bubble does not depend upon solution properties but its size and temperature. Consider a bubble (see Fig.1) made by a polymer solution, and assume that the air pressures inside and outside the bubble are respectively $P_{i}$ and $P_{o}$, its radius is $\mathrm{r}$.

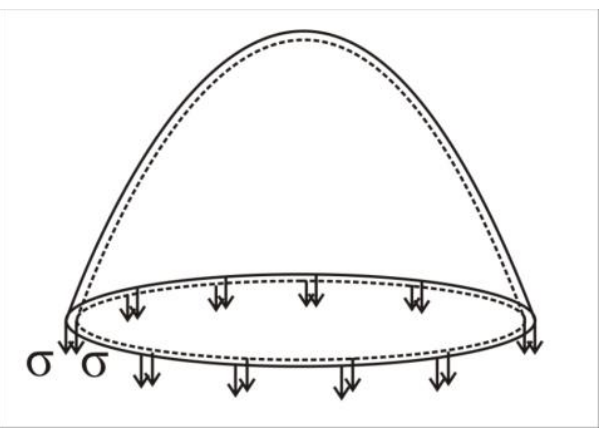

Figure 1: Surface tension of a bubble

According to the force balance, we have the following equation [1] 


$$
2 \cdot 2 \pi r \sigma=\pi r^{2}\left(P_{i}-P_{0}\right)
$$

The surface tension of a bubble can be expressed in the form

$$
\sigma=\frac{1}{4} r\left(P_{i}-P_{0}\right)
$$

This is the well-known Young-Laplace equation, Liu et al. suggested a modification [8]. Eq. (4) means the surface tension of a bubble geometrically depends upon its size. For a nano bubble, it requires a very small force to overcome the surface tension of a polymer bubble for fabrication of nanofibers. So far, we produced nanofibers with diameter of about $5 \mathrm{~nm}$ [27].

Figure 2 gives a bubble electrospinning set up. Bubbles are produced by a controllable syringe pump, and number of bubbles depends upon the size of tube. The number of bubbles reduces with decrease of the diameter of the tube, when the tube reduces to a threshold value, only a single bubble is formed [26]. A single bubble is suitable for study of the effect of various spinning parameters, such as bubble size, applied voltage, on production quality. These controlling parameters can be used during mass-production of micro/nano fibers by increasing the tube size, the tube can be also an irregular form, it can be like a pool, a square when applied for industry applications.

The voltage is applied to overcome the surface tensions of bubbles, when the voltage reaches a threshold, multiple jets are ejected from bubbles. A metal receiver above is used for collecting fibers.

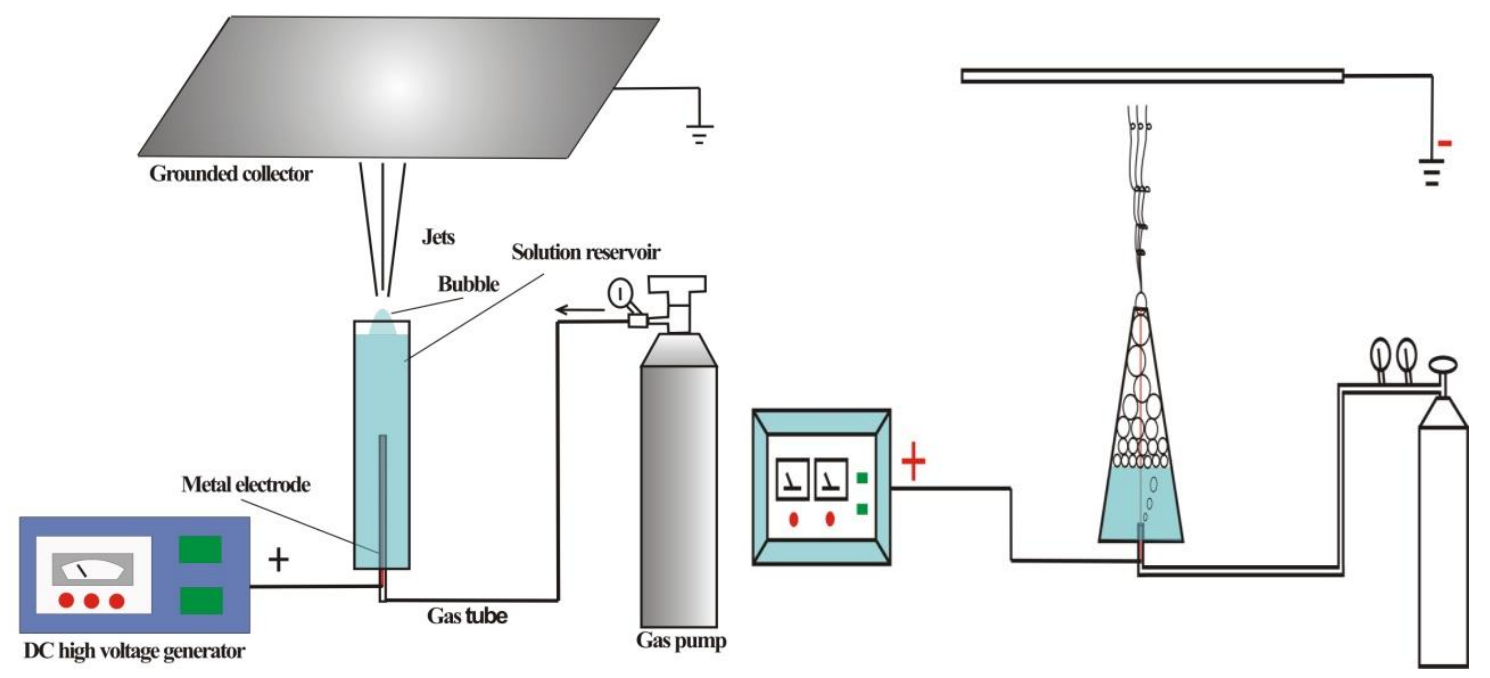

Figure 2: Bubble electrospinning setup for tunable bubble size

Assume that the velocity of the air inside of the bubble is zero, when the bubble is broken, according to Bernoulli equation, we have

$$
\frac{P_{0}}{r}+\frac{1}{2} u^{2}=\frac{P_{i}}{r}+0
$$

The velocity of the air jet can be calculated as 


$$
u=\sqrt{\frac{2 \mathrm{D} P}{r}}
$$

By the state equation, $P=a r^{k}$, where $a$ is a constant, $k=1.405$ for dry air, we have

$$
\frac{\mathrm{D} p}{p}=k \frac{\mathrm{D} r}{r}
$$

Assume that the pressure inside of the bubble $P_{i}=2$ atmospheres=202650Pa, and air density $r=1.2041$ $\mathrm{kg} / \mathrm{m}^{3}$, and $\mathrm{D} r / r=2 \%$, according to Eq. (7), that means

$$
\mathrm{D} p=1.405^{\prime} 202650^{\prime} \quad 0.02=5694.465 p a
$$

The velocity of the air jet reaches

$$
u=\sqrt{\frac{2 \mathrm{D} p}{r}}=\sqrt{\frac{2^{\prime} 2847}{1.2041}}=97 \mathrm{~m} / \mathrm{s}
$$

When a bubble is broken, the initial jet velocity is almost $100 \mathrm{~m}$ per second. Generally, the receptor distance is about $10 \mathrm{~cm}$, so the spinning process is finished within 0.001 seconds. During this short period, the fluid jet is solidified into fibers.

When a bubble is broken, film fragments are ejected with high initial velocity of about $100 \mathrm{~m} / \mathrm{s}$ and high acceleration, which are further attenuated by the electronic force, at the same time, the surface tension of the film leads to its minimal surface, as a result, cylindrical nanofibers can be obtained.

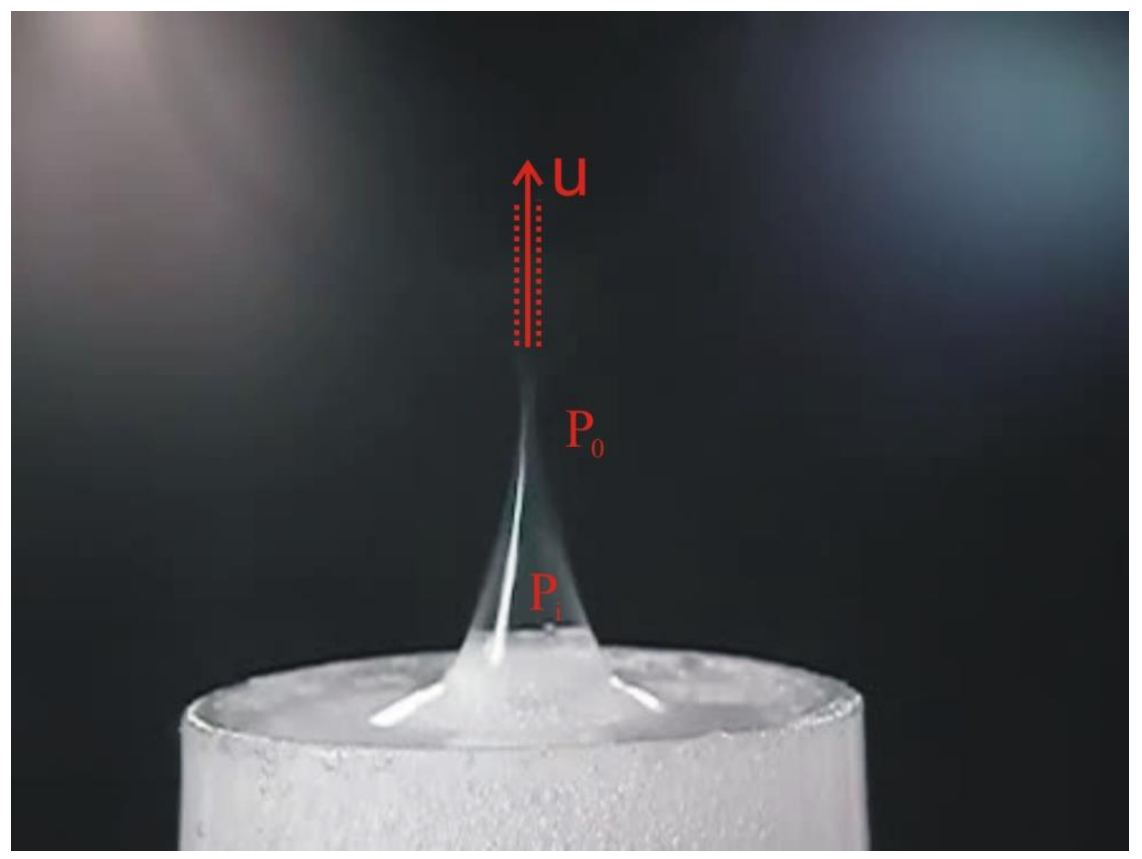

Figure 3: Air jet from a broken bubble, its initial velocity is as high as $100 \mathrm{~m} / \mathrm{s}$. 


\subsection{Effect of temperature on a bubble's surface tension}

The surface tension of a bubble can be effectively controlled by the bubble size and temperature [28]. According to state equation for ideal gas, we have

$$
\frac{P_{i}}{\rho_{i}}=R T_{i}
$$

and

$$
\frac{P_{o}}{\rho_{o}}=R T_{o}
$$

where $\mathrm{R}$ is the gas constant, $T_{i}$ and $T_{0}$ are the absolute temperatures inside and outside of the bubble,

respectively, $\rho_{i}$ and $\rho_{o}$ are densities of the air inside and outside of the bubble, respectively.

By a simple derivation, we have

$$
\sigma=\frac{1}{4} r R\left(T_{i} \rho_{i}-T_{o} \rho_{o}\right)
$$

In case $T_{i} \rho_{i}-T_{o} \rho_{o}$ is very small, i.e.,

$$
T_{i} \rho_{i}-T_{o} \rho_{o}<<1
$$

the surface tension of a polymer bubble becomes extremely small, any a small external force can be used to pull the bubble for fiber fabrication. This property is suitable for optimal design of blown bubble spinning $[\underline{11}, \underline{12}]$, a kind of Bubbfil spinning [2] .

\subsection{FIBER MORPHOLOGY PROPERTIES}

Rupture process of a bubble under an electrostatic field is illustrated in Figure 3. A ruptured bubble can produce multiple jets as shown in Figure 3. Various morphologies are observed, including continuous nanofibers, thin strips, micro-spheres and crimped nanofibers [24]. The spinning process is illustrated in Fig.4. 

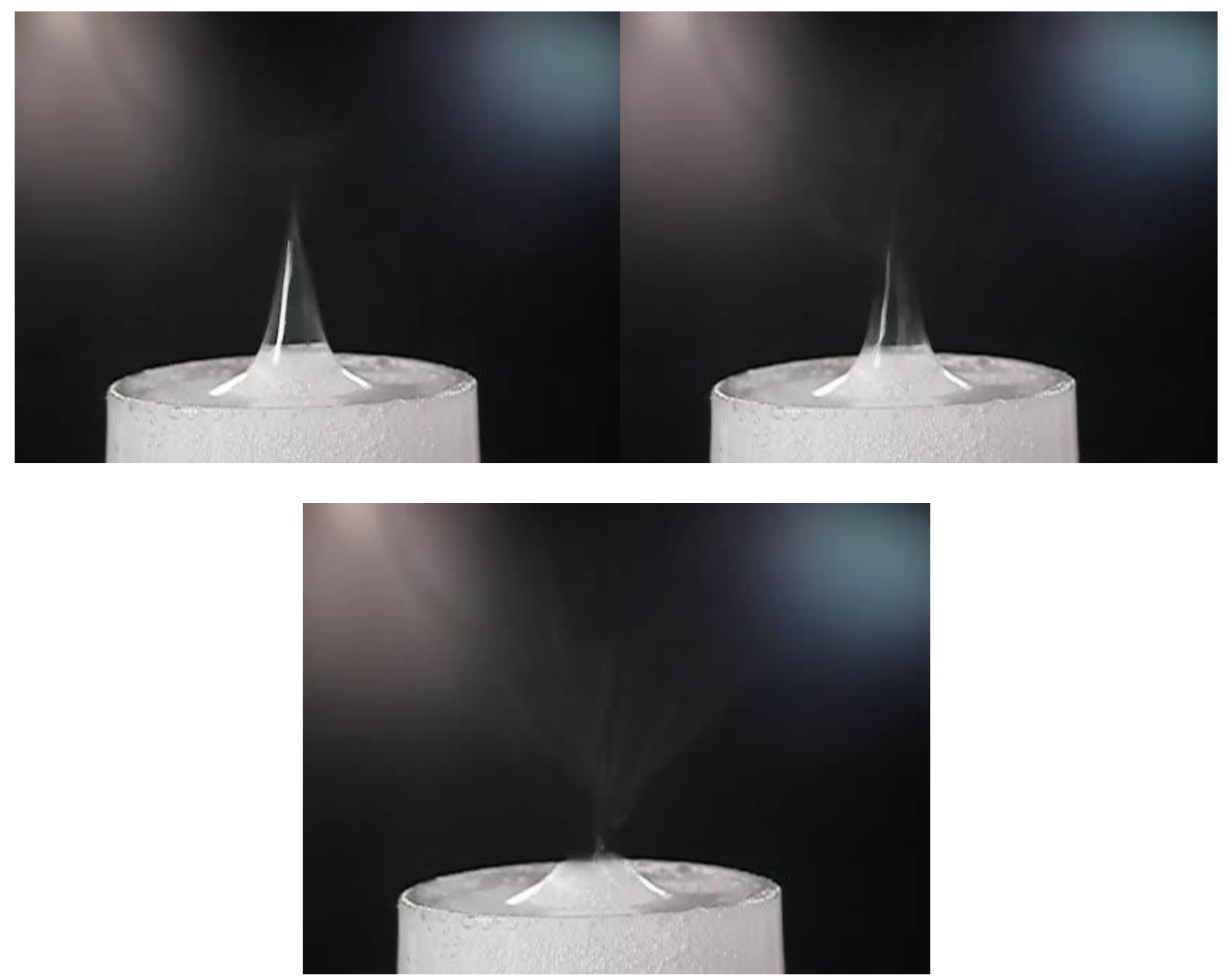

Figure 4: Rupture process of a bubble under an electrostatic field.

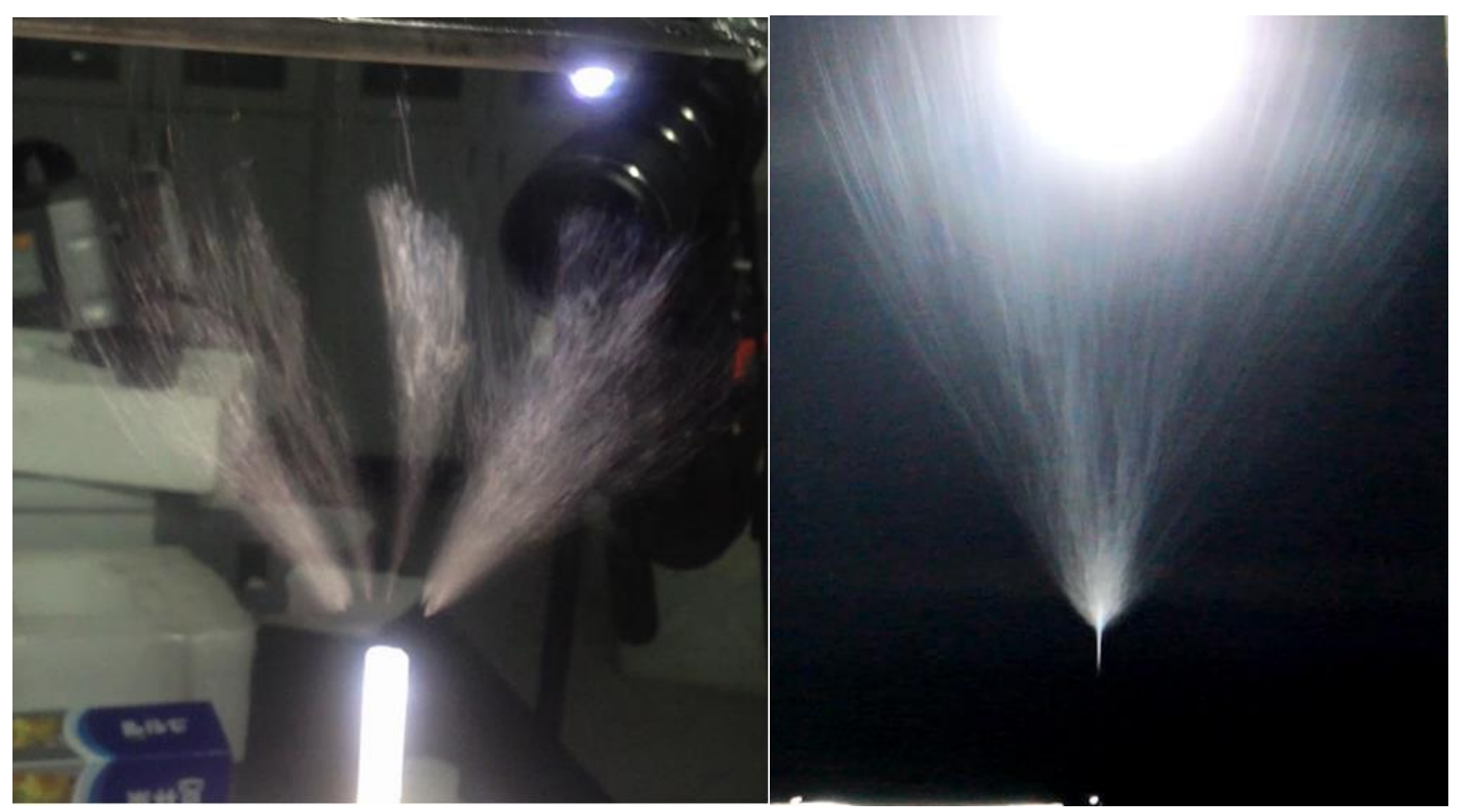

Figure 5: Multiple charged jets from a broken bubble. 


\subsubsection{Smooth cylindrical fibers}

Smooth cylindrical fibers are always obtained in Bubbfil spinning process, see Figure 5. The fiber diameter depends mainly on the wall width of the bubble and electronic filed. During the spinning process, the surface of the strip-like jet is minimized by its surface, as a result, a cylindrical fiber is obtained after solidification.

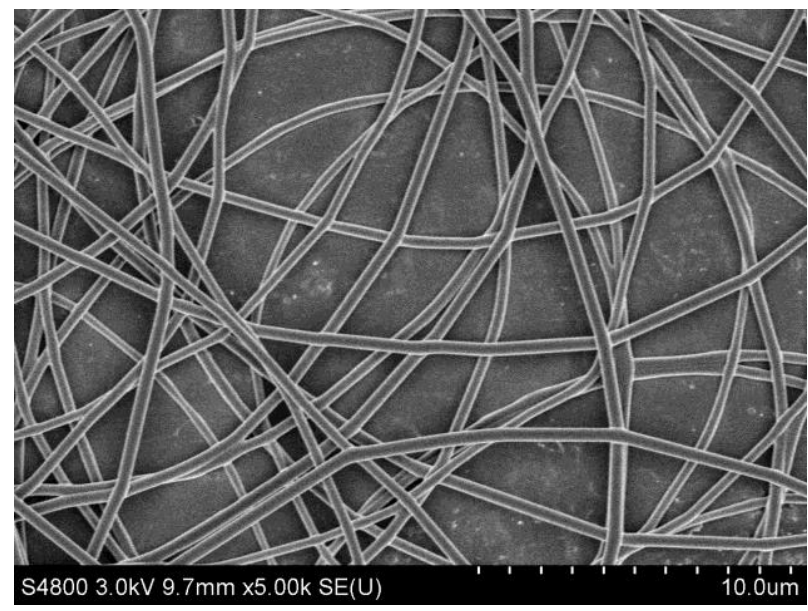

Figure 6: Smooth nanofibers by Bubbfil spinning process

\subsubsection{Hierarchical Ruptured Bubbles for Nanofiber Fabrication}

When an electric field is present, it induces charges into the bubble surface, these quickly relax to the bubble surface. The coupling of surface charge and the external electric field creates a tangential stress, resulting in the deformation of the bubble. Once the electric field exceeds the critical value needed to overcome the surface tension, the bubble is broken, and smaller daughter bubbles are formed around the broken bubble, see Figure 6, and sub-daughter bubbles are formed when a daughter bubble is broken due to the electronic field, the process continues until some a hierarchical ruptured bubble is pulled upwards to form a charged jet, which is then received on the metal receiver as nanofibers. This event typically occurs within milliseconds, Bird et al. [29] demonstrated, both experimentally and numerically, that the curved film of a ruptured bubble can fold and entrap air as it retracts. The resulting toroidal geometry of the trapped air is unstable, leading to the creation of a ring of smaller bubbles.

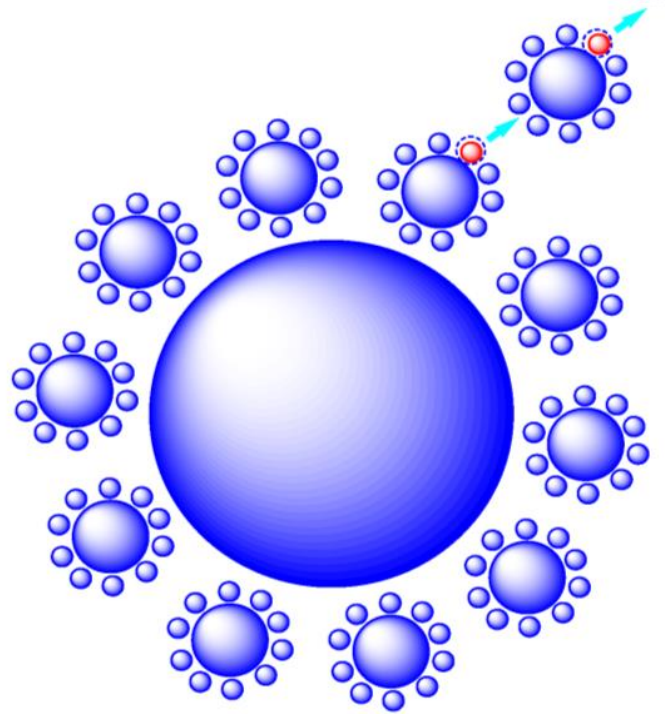

Figure 7: A broken bubble and daughter bubble cascades used for nanofiber fabrication 


\subsubsection{Nanoscale hollow fibers}

When a bubble is broken, the fragments with various forms are formed, and the minimization of surface energy and action of the electronic field result in nanoscale hollow fibers, which have many potential applications in filtration and invisibility device (e.g. stealth plane) and radiation protection.

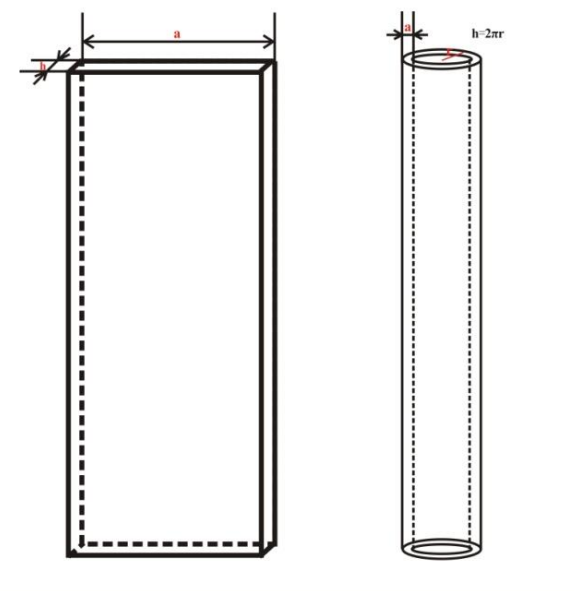

Figure 8: A nanoscale hollow fibers is formed from a thin film due to surface tension

\subsubsection{Superthin films}

Minimization of the jet surface always results in smooth fibers, however, when the width of a film is too large, the surface tension to minimize the surface area is not large enough to overcome the bending force of the film, as a result, a strip-like fiber, or a superthin film $[\underline{6}, \underline{7}]$ is obtained as illustrated in Fig.9.

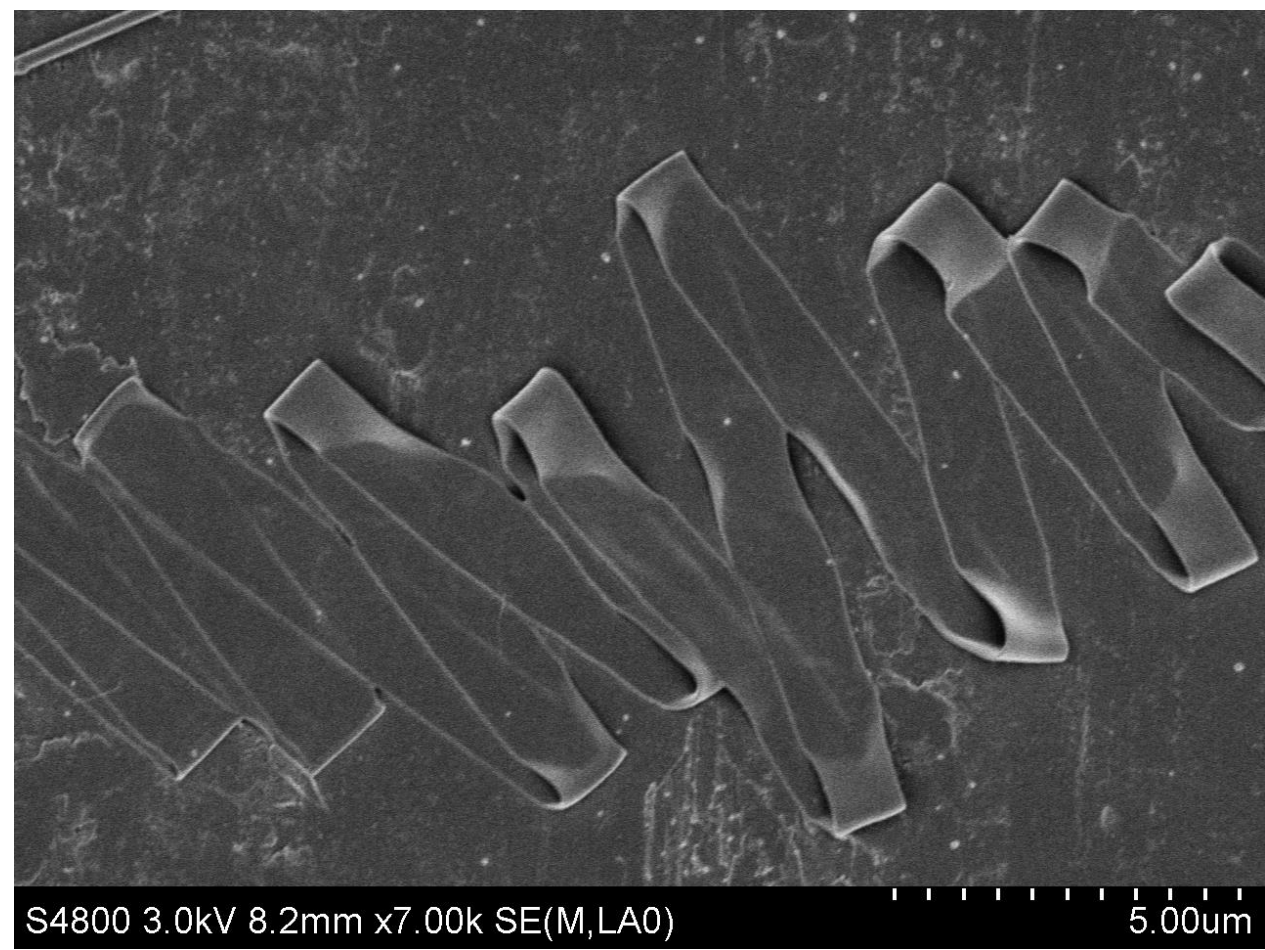

Figure 9: Superfine nanofilm with the thickness of about 20nm by bubble-electrospinning. 


\subsubsection{Nanoporous fibers}

Nanoporous fibers are formed when the solvent evaporation is extremely fast during the spinning process, as shown in Fig. 9. The solvent evaporation results in much energy lose of the moving jet, as a result, the moving velocity becomes smaller. According to mass conversation,

$\rho u A=Q$

where u is velocity, $\rho$ is the liquid density, A is the section area, $\mathrm{Q}$ is the flow rate, the diameter of the jet become bigger.

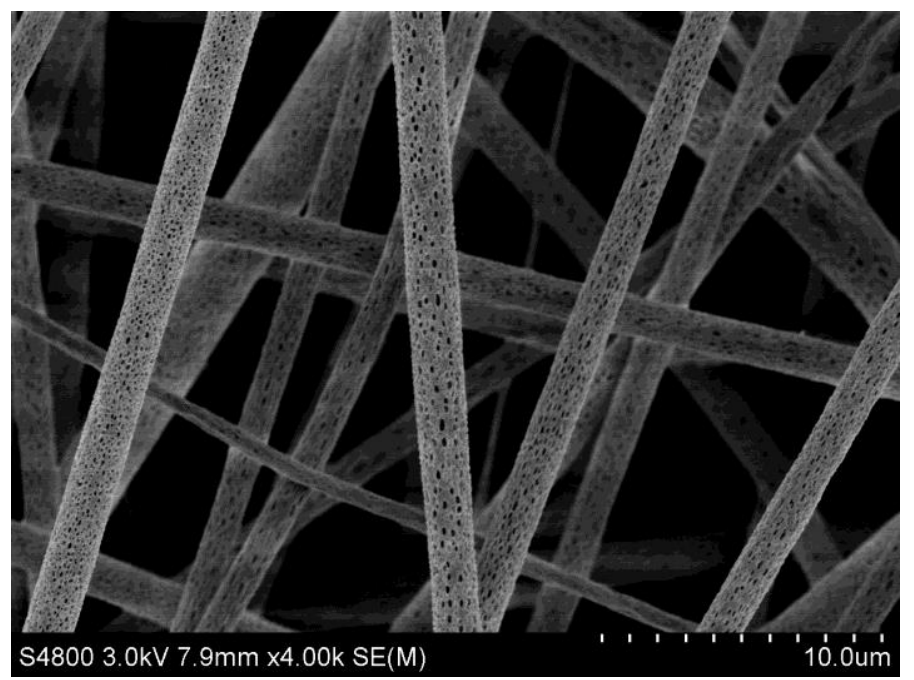

Figure 10: Nanoporous fibers with the average diameter of pores of about 50nm.

\subsubsection{Beaded fibers}

Beaded fibers are obtained due to oscillation of the moving jet. The oscillation of the jet results in change of jet radius during the spinning process, and the wave crests are solidified to beads due to the surface tension of the jet. The theoretical analysis is available in Ref.[30].

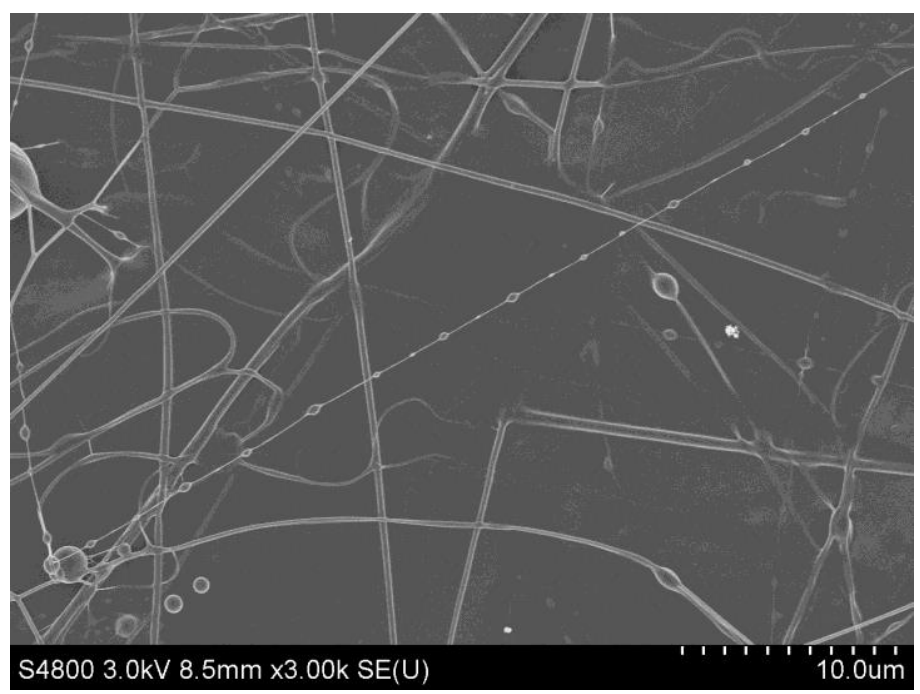

Figure 11: Beaded nanofibers by bubble-electrospinning. 


\subsubsection{Crimped nanofibers}

Transverse vibration of a moving fiber will result in crimped nanofibers, the process is similar to the stuffer box crimping for fabrication of crimped fibers [24]. Crimped fibers, especially crimped nanofibers, have many potential applications in air filtration, water filtration, radiation protection, fuel cell, and many others due to high surface-to-volume ratio. The mechanism of fiber crimp is due to the transverse vibration of an axially moving slender fiber of viscoelastic fluid before solidification.

The velocity of the axially moving slender fiber plays a key role in mass-production of crimped fibers. A higher velocity is much needed for a higher production ratio, however an increase of $u$ might result in no transverse vibration, as a result, no crimped fibers can be produced. Therefore, it is necessary to pick out the main factors affecting the critical velocity of the axially moving slender fiber, a complete theoretical analysis is available in Ref. [24].

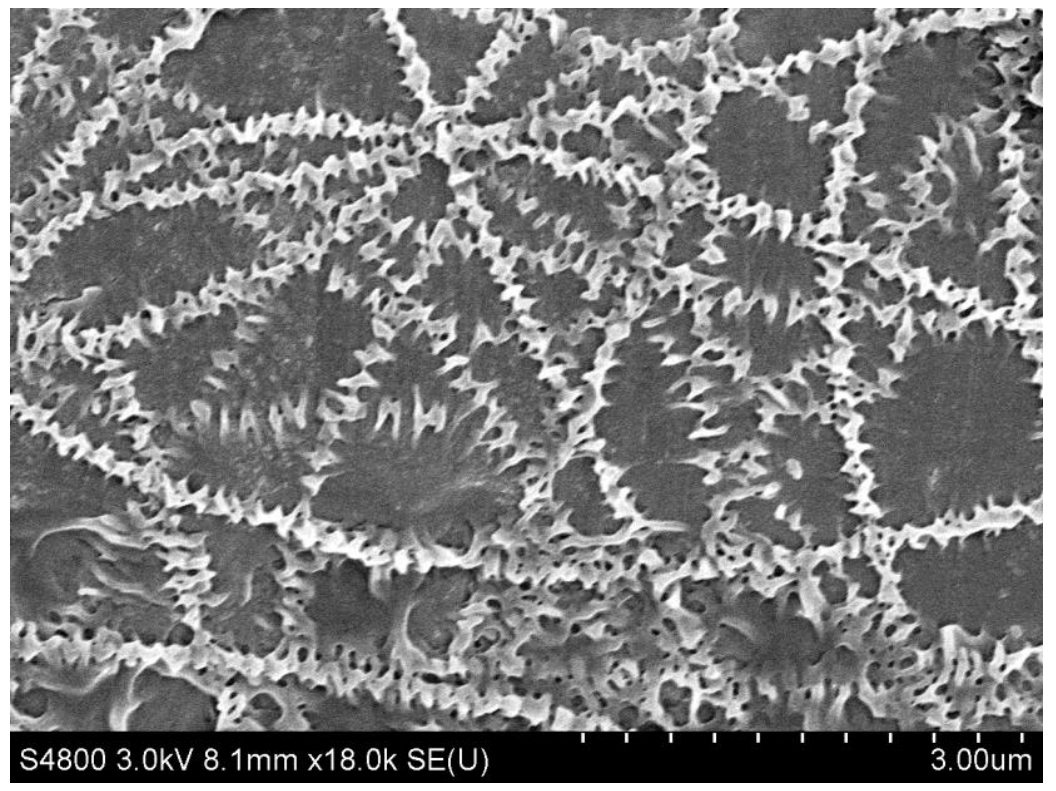

Figure 12: Crimped fibers by bubble-electrospinning by Bubbfil spinning

\subsubsection{Orientation nanofibers}

Orientation nanofibers can be obtained by double or multiple receptors with same electrostatic potential. The charged jet during the spinning process moves from high potential to low one. If the two parallel wires with same potential, the fibers will be received as orientated ones as illustrated in Fig. 13.

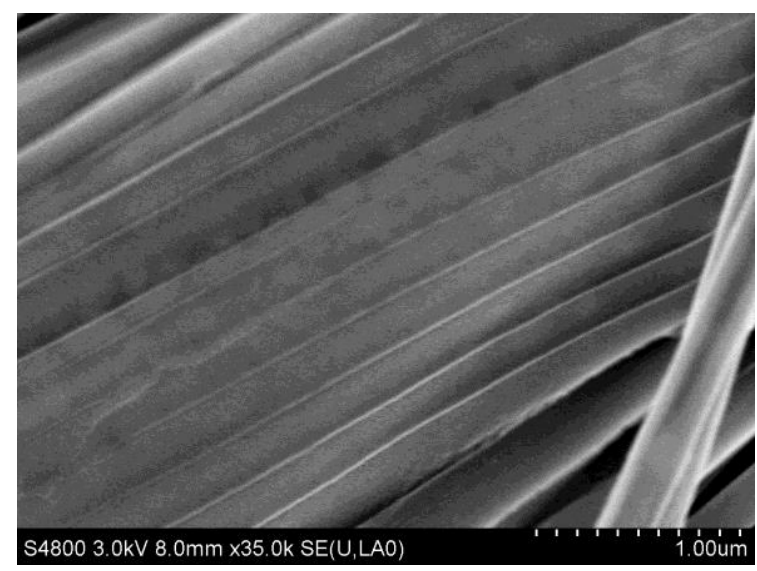


Figure 13: Orientation nanofibers by bubble-electrospinning

\subsubsection{Micro Yarn}

Recent years, much attention has been paid to approaches for directly producing nanofibers along with a rising trend for their exploration and application in wide fields. Considering the melt blowing and bubbleelectrospinning, a novel method called blown bubble spinning was introduced by forcing airflow onto the polymer bubble. Other morphologies by Bubbfil spinning method are summarized in Tab.1[1].
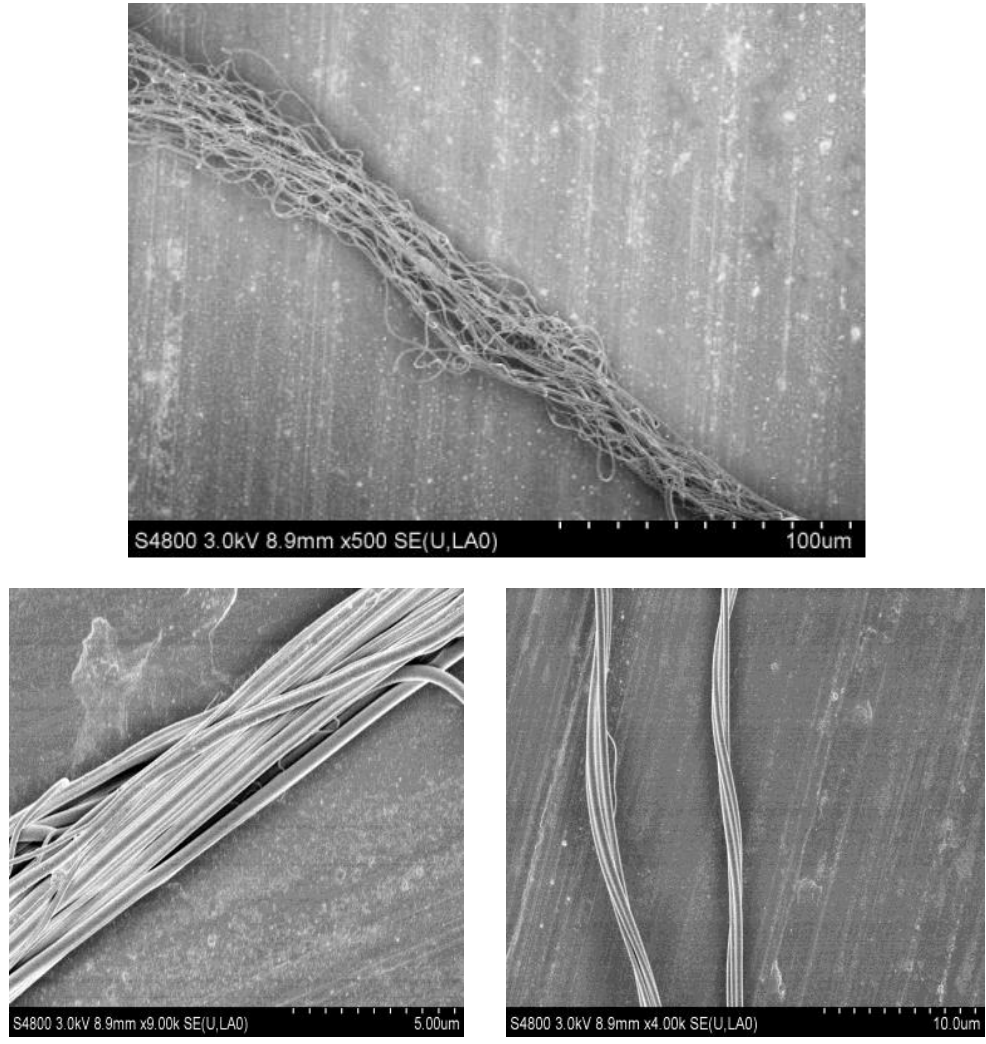

Figure 14: SEM of a micro yarn by the blown bubble-spinning [11]

Table 1: Morphologies of the various obtained materials by the bubble electrospinning

\begin{tabular}{|c|c|}
\hline $\begin{array}{l}\text { CONDITIONS ( } \mathrm{a} \text { is width, } \mathrm{h} \text { is thickness } \\
\text { of the film of the bubble) }\end{array}$ & MORPHOLOGIES \\
\hline$a<10.6 h$ & Irregular particles \\
\hline$a=10.6 h$ & Spheres with diameter of $6 \mathrm{~h}$ \\
\hline $10.6 h<a<4 \pi h$ & $\begin{array}{l}\text { Irregular structure between sphere and fiber, spind le-like, diamond-like and ellipsoid } \\
\text { structure. }\end{array}$ \\
\hline$a=4 \pi h$ & Cylindrical fibers with diameter of $4 \mathrm{~h}$ \\
\hline$a>4 \pi h$ and $a>\alpha \sqrt{h \lambda}$ & Stable strips \\
\hline$a=\alpha \sqrt{h \lambda}$ & Discontinuous backbone-like wrinkled materials \\
\hline$a>>4 \pi h$ & Daughter bubbles \\
\hline
\end{tabular}

\section{BUBBFIL SPINNING PROCESS}

Bubbfil spinning including bubble electrospinning, blown bubble spinning, membrane spinning using electric force or blowing air or mechanical force to overcome the surface tension of bubbles or membranes of the spun solutions. 


\subsection{Blown bubble spinning}

Blown bubble spinning is to use blowing air to overcome the surface tension of a polymer bubble without electronic force $[\underline{1}, \underline{6}, \underline{11}]$, which is used commercially as a one-step process for converting polymer resin directly into a nonwoven mat of fibers or yarns. In the process, a very high velocity gas impacts a polymer bubble as illustrated in Figure 15. As a result, the bubble is broken, and the blowing air, the resultant fibers are collected upon a screen as a nonwoven mat or nano/micro-fiber yarn, attenuates multiple jets rapidly.

The blown bubble spinning can be greatly enhanced by adding a small electronic field, the process is called as electrostatic-field-assisted blown bubble spinning, see Figure 16, which can also be used as air-jet assisted bubble electrospinning depending upon the main acting force.

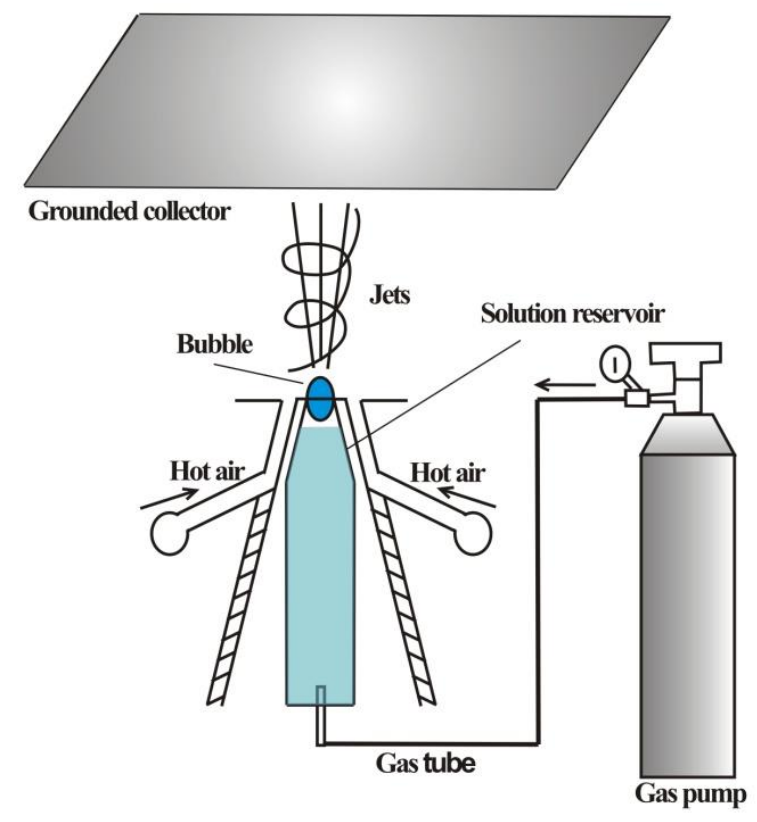

Figure 15: Blown bubble spinning. The acting force is the blowing air instead of electronic force

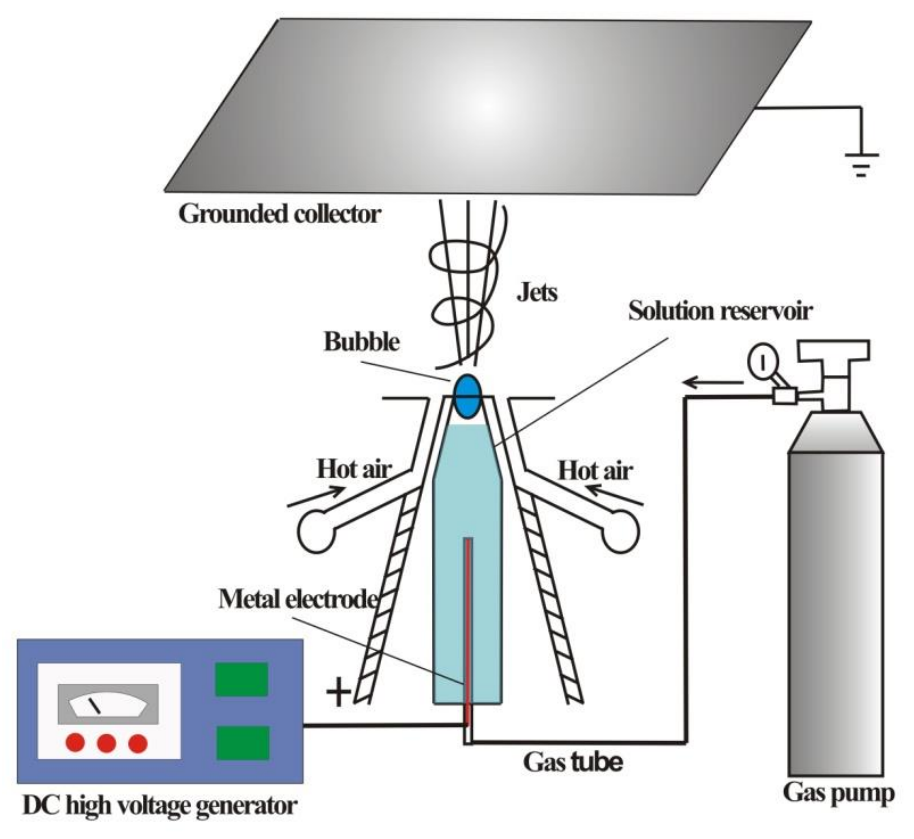


Figure 16: Air-jet assisted bubble electrospinning or electrostatic-field-assisted blown bubble spinning

When a small electrostatic field is applied, which does not exceed the threshold for breaking the bubble, the wall thickness of the bubble become much thinner, and a blowing air can be used as an acting force in the spinning process. On the other hand, we can use a small airflow to control the air pressure and temperature outside the bubble. According to Eq. (12), we can adjust the surface tension of a bubble easily.

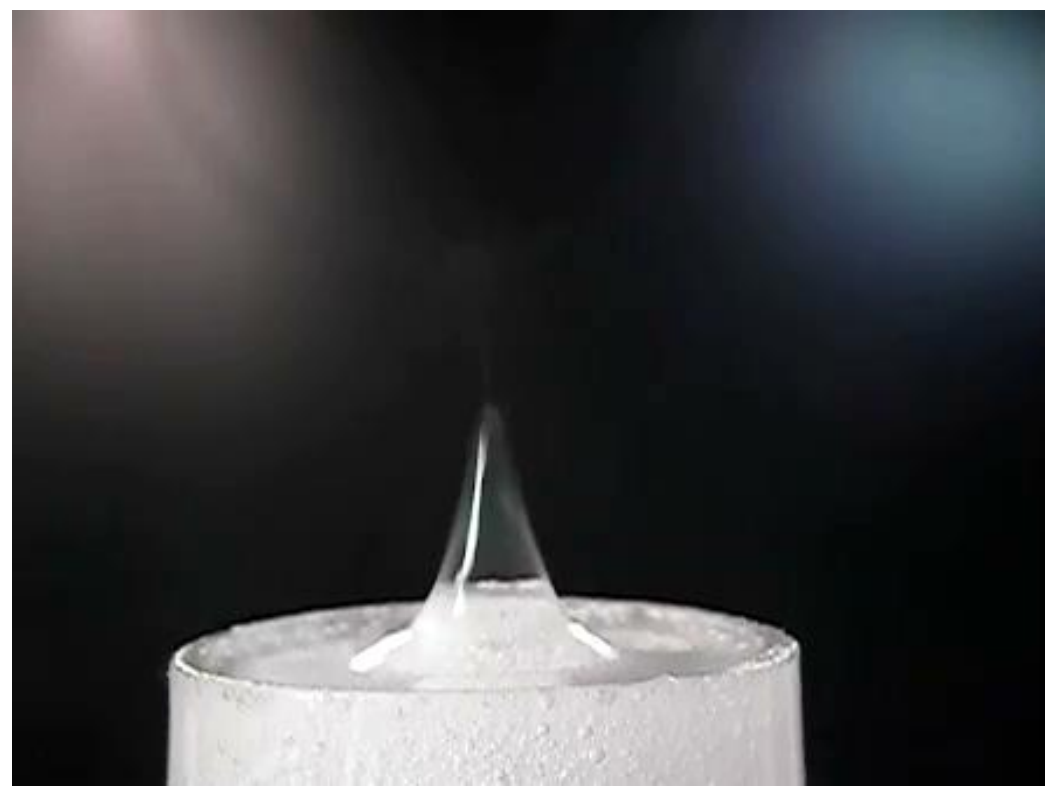

Figure 17: A polymer bubble in presence of an electrostatic field

\section{2 Ultrasonic-assisted bubble electrospinning}

The spinability of classical electrospinning is greatly limited, not every polymer solution or melt can be used for fabrication of nano/micro fibers, because highly viscous solution will block spinnerets [23, $\underline{31}-\underline{34}]$. However, bubble electrospinning can be powerfully applied if a bubble can be formed on the solution or melt surface. For example, Poly (ethylene oxide) (PEO) solution is of high viscosity, and it cannot be used alone for fabrication micro/nano fibers by electrospinning. To show this we conduct an experiment as follows [23] .

Material: Polyethylene oxide (PEO) with a molecular weight of 600,000 , at a weight concentration of $4 \%$, was dissolved in a mixture of $50 \%$ distilled water and $50 \%$ ethanol. The obtained solution is of high viscosity, see Figure 18.
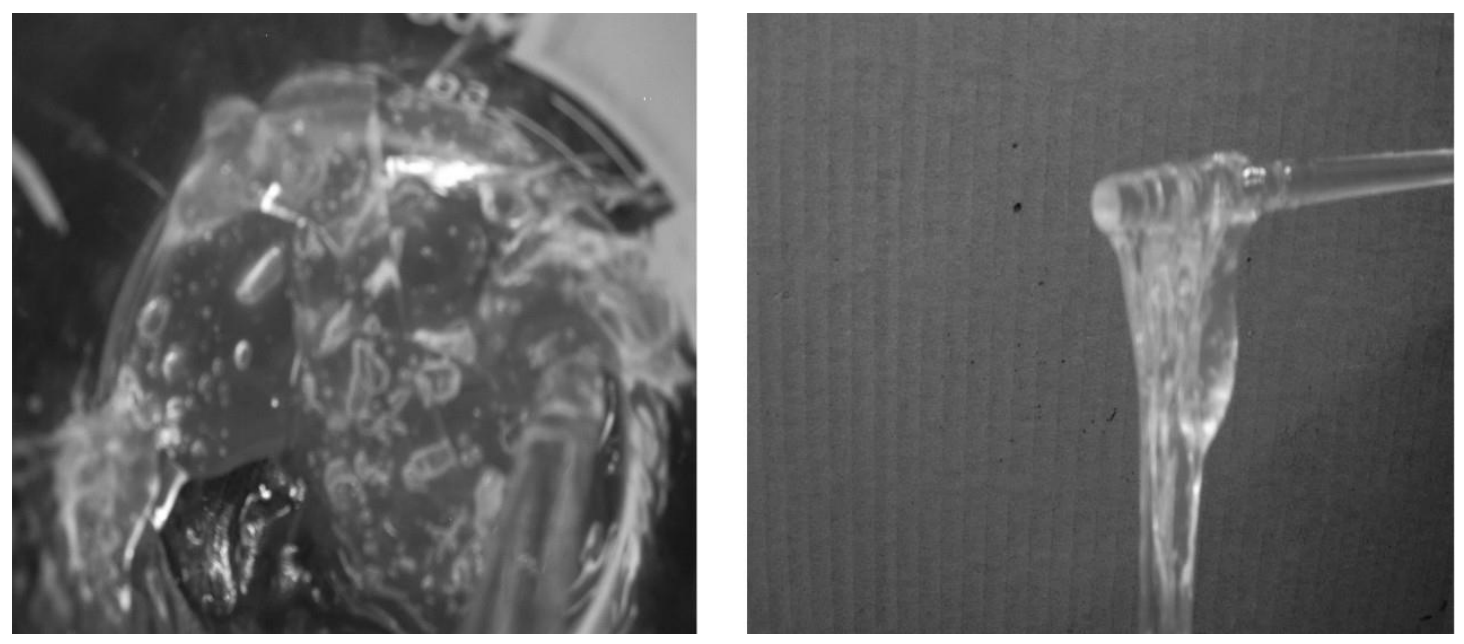
Figure 18: Coagulated PEO solution, which can be spun by classic electrospinning

Our observation shows that the viscosity greatly affects the bubble size and bubble number, which are two important factors in bubble electrospinning. Multiple bubbles are formed on the solution surface, and smaller bubbles will be merged into the bigger ones, making the bubble electrospinning relatively difficult.

To solve the problem, we found that small tube for the solution container is much suitable for highly viscous solutions. When the diameter of the container tube reduces to $11 \mathrm{~mm}$, the spinning process can be well performed. In order to increase output of PEO nanofibers, multiple container tubes should be used.

The spinability of bubble electrospinning for high viscous PEO solution can be enhanced by ultrasonic vibration, see Fig.19. When a ultrasonic vibration is added to the solution, its viscosity reduces greatly, and its spinability increases greatly, additionally when ultrasonic vibration induces oscillation of a bubble, when the frequency of ultrasonic vibration closes to the natural frequency of the bubble, resonance occurs, which explodes the bubble with an extremely ejecting velocity of the fragments. According to the mass conservation for one-dimensional steady flow, see Eq.(14), higher velocity of the spinning jets results in smaller of fibers. According to Ref.[35], the minaret resonance can be expressed as

$w=\frac{1}{2 p r} \sqrt{\frac{3 g p}{r}}$

Eq.(15) implies a smaller bubble results a higher minaret resonance. A detailed discussion on effect of ultrasonic vibration on the spinning process is available in Ref.[36].

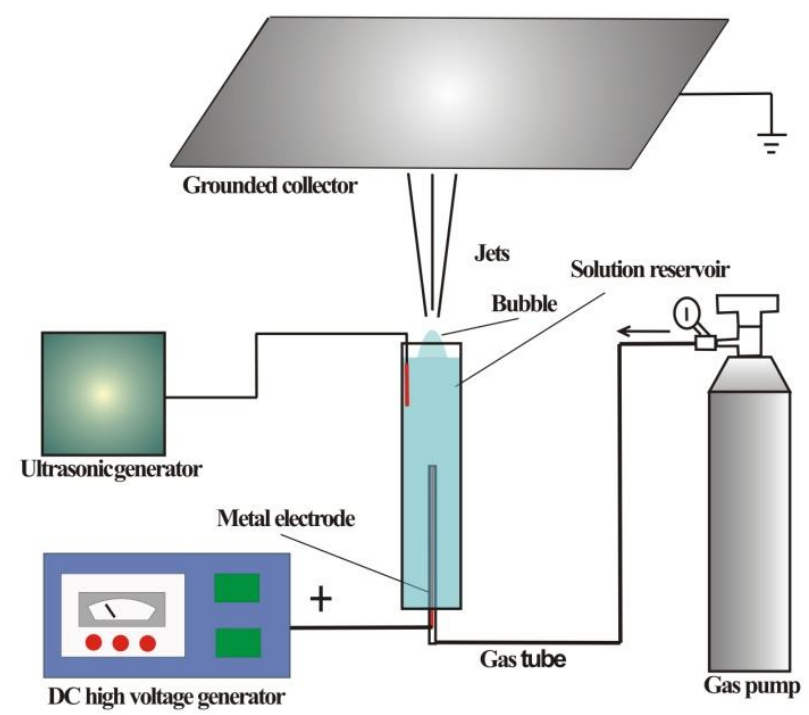

Figure 19: Ultrasonic-assisted bubble electrospinning

\subsection{Bubble size control}

The surface tension of a bubble depends upon its size; a smaller bubble requires a smaller electronic force for fabrication of ultrafine fibers. When the electronic force triggers rupture of a bubble, the spinning process is finished immediately within 0.001 seconds, and a new bubble is to be formed for continuous fabrication. In order to study the effect of frequency of the bubble formation on the spinning process, we design a new experimental set-up. 
The new experimental set-up is illustrated in Figure 20. A single bubble is produced on the top of the roller, the size of the bubble is controllable by the whole diameter on the roller's surface, which is connected with the gas suppler. When the roller rotates, the bubble, under the electronic force, is broken, and multiple jets are formed, which are received on the metal receiver above as nanofibers.

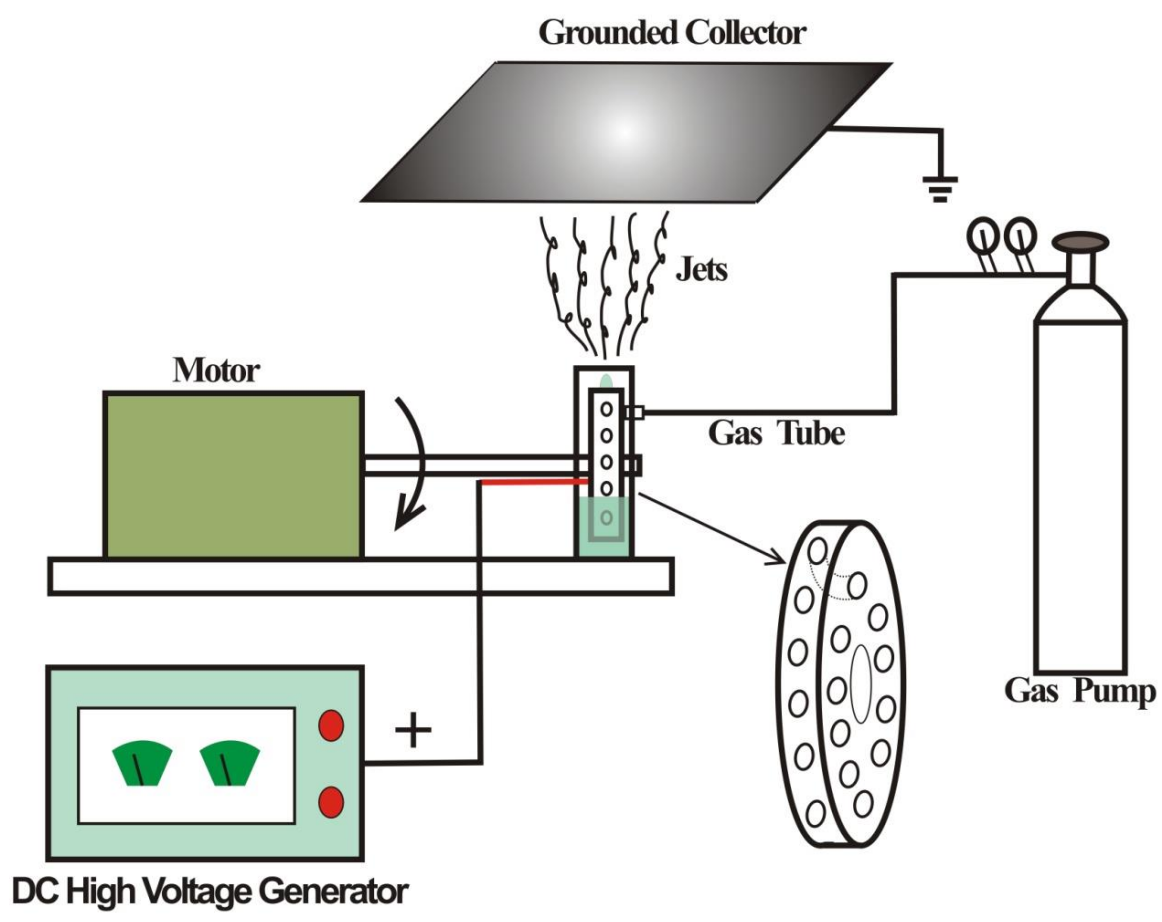

Figure 20: The experimental set-up of the bubble electrospinning.

Another bubble is produced when the adjacent hole reaches its top, so the motor can exactly control the frequency of the bubble formation.

In the spinning process, the motor can exactly control the bubble formation frequency mechanically, and the bubble size depends mainly on the whole size and the pressure and velocity of the input air. The experiment shows that a continuous spinning process is realized with almost same bubble size for nanofiber fabrication.

\subsection{Other modifications}

Recently Gule et al. successfully applied the bubble electrospinning to mass-production of furanone-containing poly (vinyl alcohol) nanofibers for cell-adhesion inhibition [37], they found that an electric field of a much higher voltage than those used in conventional needle spinning is necessary, this is different from the previous practice [1], and it is very necessary to find the main problem. 


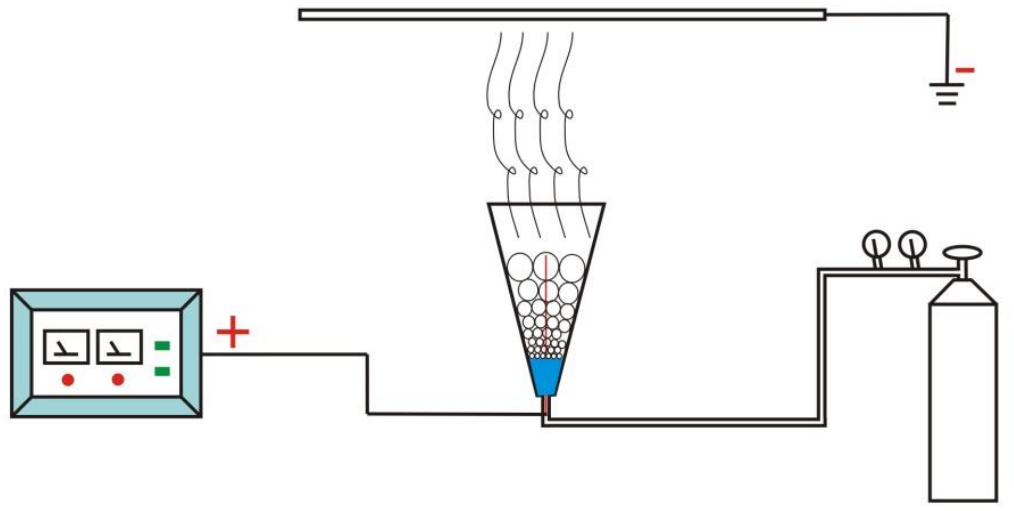

Figure 21: Gule et al.'s bubble electrospinning set-up

In the bubble electrospinning as illustrated in Figure21, multiple bubbles are produced on the surface the spun solution, where bubbles are interacted with each other, and smaller ones will bulge into a larger bubble, as a result the bubbles grow up larger and larger in the bubble container as illustrated in Figure21, which was used by Gule et al.[37]. According to Eq. (1), it requires a higher voltage for a larger bubble. In our experimental observation, large bubbles are difficult for spinning, and the bubbles will flow over the edges of the container into the ground.

In a multiple bubble electrospinning, the interaction of bubbles results in a higher voltage, and in some case only the daughter bubbles of a ruptured large bubble can be used for producing fibers [1], see Figure 22, photos of the multiple ellectrospinning process, where smog-like multiple jets are produced mainly by daughter bubbles of a ruptured large bubble.

To overcome the problem arising in multiple bubble electrospinning, a single bubble electrospinning was proposed [21], and an inverted cup-like bubble container as illustrated in Figure 2 might be more suitable for experimental use.

Multiple bubbles are interacted with each other within the bubble container, and a single bubble is formed on the top of the container if its diameter is small enough. The frequently produced bubble on the top container has almost same size, as a result, morphology of the nanofibers can be easily controlled by adjusting the bubble's diameter.

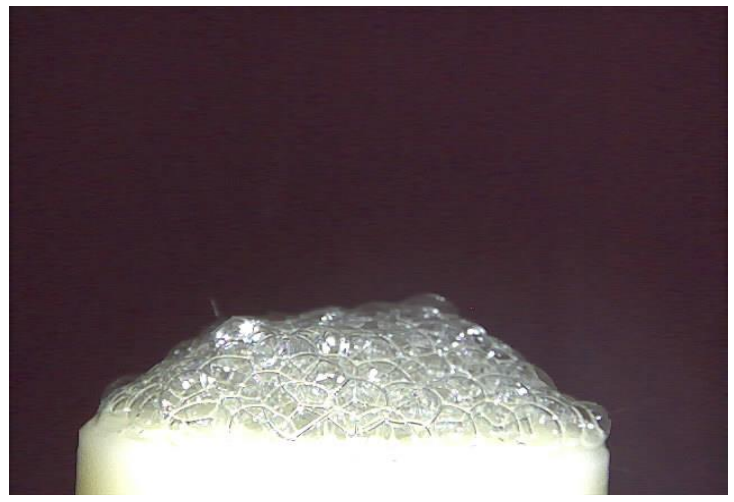

Figure 22: Multiple bubble electrospinning. Larger bubbles cannot used for fiber fabrication

Recently Pu et al. claimed that, they proposed a novel enclosed air-jet electrospinning, see Fig.24 [38]. This paper concludes that the so-called novel electrospinning is exactly the bubble electrospinning. Fig.24 
shows the same spinning process as given in Fig.2.

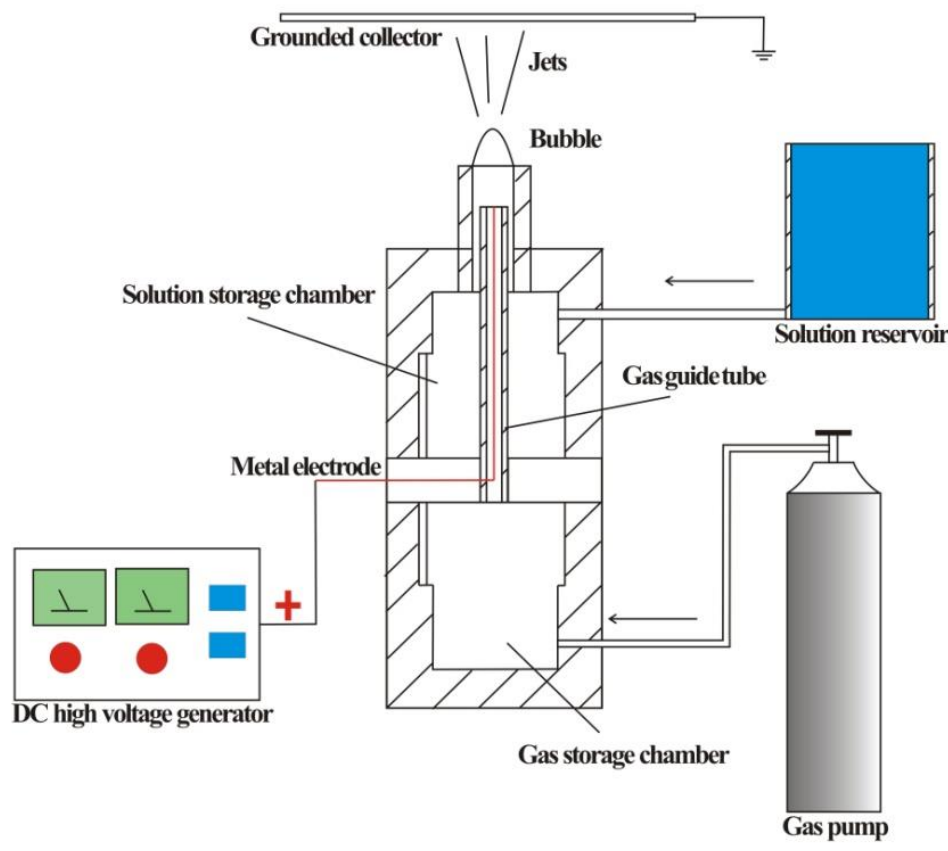

Figure 23: Pu et al.'s bubble electrospinning set-up

\section{SUMMARY}

Nanoscience bridges between the deterministic classic mechanics and the in deterministic quantum mechanics [39]. As pointed out by El Naschie [39], nanotechnology for the scientific and economic revival is of indispensable importance. Similar to the nuclear age, and maybe far more so, the nanoage will be something of a Hemingway line of demarcation between the have and the have notes, and Bubbfil spinning provides the best candidate for mass-production of nanofibers. The ejection velocity in the Bubbfil spinning process can be as high as $100 \mathrm{~m} / \mathrm{s}$, and the spinning process is finished within 0.001 seconds, the minimal diameter of the obtained fiber is as small as $5 \mathrm{~nm}$. The morphologies by Bubbfil spinning can be controlled by various methods for various applications, especially the nanoprous fibers, crimped nanofibers can be applied in catalytic and hydrogen-storage systems, invisibility device (e.g. stealth plane), and radiation protection.

\section{ACKNOWLEDGMENTS}

The work is supported by Priority Academic Program Development of Jiangsu Higher Education Institutions (PAPD), National Natural Science Foundation of China under grant No. 11372205 and Project for Six Kinds of Top Talents in Jiangsu Province under grant No. ZBZZ-035, Science \& Technology Pillar Program of Jiangsu Province under grant No. BE2013072, Jiangsu Province Key Laboratory No.KJS1314 and Jiangsu Planned Projects for Postdoctoral Research Funds 1401076B.

\section{BIBLIOGRAPHY}

[1] HE, J.H., KONG, H.Y., YANG, R.R., et al., "Review on fiber morphology obtained by bubble electrospinning and blown bubble spinning", Thermal Science, v. 16, n.5, pp. 1263-1279, 2012.

[2] HE,J.H., KONG,H.Y., et al. "Variational iteration method for Bratu-like equation arising in electrospinning”, Carbohydrate polymer, v.105, pp.229-230, 2014

[3] LIU,Y.,HE, J.H., "Bubble electrospinning for mass production of nanofibers", Int. J. Nonlin. Sci. Num., v.8,n.3, pp. 393-396, 2007

[4] HE, J.H., LIU, Y., et al., "BioMimic fabrication of electrospun nanofibers with high-throughput", Chaos Soliton. Fract. v.37, n.3, pp. 643-651, 2008. 
[5] LIU,Y., HE, J.H., et al. "The principle of bubble electrospinning and its experimental verification”, $J$. Polym. Eng.,v. 28, pp. 55-65, 2008.

[6] DOU, H., LIU, H.Y., et al. "A belt-like superfine film fabricated by bubble-electrospinning”, Thermal Science, v. 17, n. 5, pp. 1508-1510, 2013

[7] KONG, H.Y., HE, J.H., "Superthin combined PVA-graphene film", Thermal Science, v.16, n.5, 1560-1561, 2012.

[8] LIU,F.J., DOU, H. "A modified Young-Laplace equation for the bubble electrospinning considering the effect of humidity", Thermal Science, v. 17, n. 5, pp. 629-630, 2013

[9] YANG, R.R., HE, J.H., XU, L., et al.,"Bubble-electrospinning for fabricating nanofibers", Polymer, v.50,N. 24, pp. 5846-5850, 2009

[10] CHEN, R.X. "Burst of a fast axially moving micro/nano jet", Bubbfil Nanotechnology, v. 1, n.1, pp.13-23, 2014

[11] DOU, H., ZUO, B.Q., HE, J.H.,"Blown bubble-spinning for fabrication of superfine fibers", Thermal Science,v. 16,n.5, 1465-1466, 2012.

[12] DOU,H., LIU,H.Y., MO, L.F.,” Blown bubble-spinning and micro yarns”, Bubbfil Nanotechnology, v. 1, n.1, pp. 24-28, 2014

[13] KONG, H.Y., He, J.H., et al., "Polymer liquid membrane for nanofiber fabrication”, Thermal Science, v. 17 , n. 5, pp. 1479-1482, 2013

[14] KONG, H.Y., HE,J.H. “A Modified Bubble Electrospinning for Fabrication of Nanofibers”, Journal of Nano Research, v. 23, pp. 125-128, 2013

[15] XU, L., SI, N., Lee, E.W.M., et al., “ A multi-phase flow model for electrospinning process”, Thermal Science, v. 17, n. 5, pp. 1299-1304, 2013

[16] LI, H.B., KONG,H.Y., et al., "Particle-like beads and daughter jet cascades in electrospinning", Thermal Science, v. 17, n. 5, pp. 1421-1424, 2013

[17] PANG, J., KONG, H.Y., et al., "PVA-based nanographene film by electrospinning", Thermal Science, v. 17, n. 5, pp. 1449-1452, 2013

[18] WANG, P., HE, J.H. "Electrospun polyvinyl alcohol-milk nanofibers", Thermal Science, v. 17, n. 5, pp. 1515-1516, 2013

[19] WANG, P., HE, J.H. “Electrospun polyvinyl alcohol-honey nanofibers”, Thermal Science, v. 17, n. 5, pp. $1549-1550,2013$

[20] PELOFSKY,H., J. Chem. Eng. Data, v.11, pp. 394-397, 1966.

[21] REN, Z.F., LIU, B.Z., SHAO, Z.Y., et al., "Allometric scaling law between average polymer molecular weight and electrospun nanofiber diameter", Journal of Polymer Enegineering, v. 28, pp.19-26, 2008

[22] TATRO,S.R.,B AKER,G.R., et al., "Matrix-assisted laser desorption/ionization(MALDI) mass spectrometry: determining Mark-Houwink-Sakurada parameters and analyzing the breadth of polymer molecular weight distributions", Polymer, v.43, pp. 2329-2335, 2002

[23] WAN, Y.Q., HE,J.H., et al., "Electrospinning of high-molecule PEO solution", Journal of Applied Polymer Science, v. 103, n.6, pp.3840-3843 , 2007

[24] CHEN, R.X., ZHANF,L., et al., "Mechanism of nanofiber crimp”, Thermal Science, v. 17, n. 5, pp. $1473-$ 1477,2013

[25] HE, J.H., LIU, Y.," Control of bubble size and bubble number in bubble electrospinning", Computer and Mathematics with Applications , v.64 , 1033-1035, 2012.

[26] REN, Z.F., HE, J.H.”Single Polymeric Bubble for the Preparation of Multiple Micro/Nano Fibers", Journal of Applied Polymer Science, v.119, pp. 1161-1165, 2011.

[27] KONG, H.Y., HE,J.H. "Electrospinning for fabrication of nanofibers with minimal diameter of about 5 nm”, Journal of Controlled Release, ,v. 172, n. 1, pp. E127-E128, 2013

[28] HE, J.H.," Effect of temperature on surface tension of a bubble and hierarchical ruptured bubbles for nanofibers fabrication", Thermal Sci., v.16, n.1, pp. 327-330, 2012 
[29] BIRD,J.C., et al. "Daughter bubble cascades produced by folding of ruptured thin films", Nature, v. 465, 759,2010

[30] HE, J. H.; KONG, H. -Y. "Criterion for an oscillatory charged jet during the bubble spinning process", Scientia Iranica, v. 21, n. 1, pp.98-100, 2014

[31] WAN, Y.Q. , HE,J.H., YU,J.Y.,WU, Y., , Vibrorheological effect on electrospun polyacrylonitrile (PAN) nanofibers", Mater. Lett., v.60, pp. 3296-3300, 2006.

[32] WAN,Y.Q., HE, J.H., YU,J.Y., et al.," Electrospinning of high-molecule PEO solution”, J. Appl. Polym. Sci., v.103,n.6, pp. 3840-3843,2007.

[33] WAN, Y. Q., HE, J.H., YU, J.Y., et al., "Carbon nanotube-reinforced polyacrylonitrile nanofibers by vibration-electrospinning”, Polym. Int., v.56, n.11, pp. 1367-1370,2007.

[34] WAN,Y.Q., HE,J.H. WU,Y., et al., "Vibrorheological effect on electrospun polyacrylonitrile (PAN) nanofibers", Mater. Lett., v.60, n.27, pp.3296-3300, 2006.

[35] MINNAERT, M., "On musical air-bubbles and the sound of running water", Philosophical Magazine, v.16, n.10, pp. 235-248,1933

[36] LIU, H.Y.; KONG, H.-Y.; et. Al., "Lightning-like Charged Jet Cascade in Bubble Electrospinning with Ultrasonic Vibration", Journal of Nano Research, v. 27 , pp. 111-119, 2014

[37] GULE, N. P., et al., "Furanone-containing poly(vinyl alcohol) nanofibers for cell-adhesion inhibition", Water Research,v. 47, pp. 1049-1059, 2013.

[38] PU, C., HE, J., CUI, S., GAO, W., Fiber. Polym.,v. 14, p.382, 2013

[39] EL NASCHIE, M.S."Nanotechnology for the developing world", Chaos, Solitons \& Fractals, v. 30, n. 4, pp.769-773, 2006 